\title{
Article \\ What Makes Companies to Survive over a Century? The Case of Dongwha Pharmaceutical in the Republic of Korea
}

\author{
Moon Young Kang
}

check for updates

Citation: Kang, M.Y. What Makes Companies to Survive over a Century? The Case of Dongwha Pharmaceutical in the Republic of Korea. Sustainability 2022, 14, 946 https://doi.org/10.3390/su14020946 Academic Editors: Francesco Caputo and Lasse Torkkeli

Received: 24 November 2021 Accepted: 11 January 2022

Published: 14 January 2022

Publisher's Note: MDPI stays neutral with regard to jurisdictional claims in published maps and institutional affiliations.

Copyright: (c) 2022 by the author. Licensee MDPI, Basel, Switzerland This article is an open access article distributed under the terms and conditions of the Creative Commons Attribution (CC BY) license (https:// creativecommons.org/licenses/by/ $4.0 /)$.
Department of Entrepreneurship and Small Business, College of Business Administration, Soongsil University, Seoul 06978, Korea; mkang@ssu.ac.kr

\begin{abstract}
Considering their significant impacts on national economy, local communities, employees, suppliers, and other stakeholders, firm survival is an important goal for most companies. However, firm longevity is not an easy result to achieve, and it becomes more difficult as business environments shift dramatically. The average life span of companies listed in Standard and Poor's 500 was 61 years in 1958, but it fell to less than 18 years in 2016. Nevertheless, more than 3000 companies over 200 years old still operate in Japan, mostly family inherited small and medium enterprises (SMEs), and Germany has many centenarian companies, especially in the manufacturing industry. However, in the Republic of Korea, with over 4000 years of history, there are no companies older than 200 years and only seven companies with over 100 years of history. Centenarian companies in Korea are very limited, and even after surviving over 100 years, they continue to face severe challenges they need to overcome in order to survive. However, it is not clearly proven what factors affect the survival of companies for over a century. Since SMEs contribute to the economic development and survival of a country, it is important to investigate the secrets of their longevity, which has become even more difficult than ever. However, as there is very limited research on firm longevity, the findings from this case study of Dongwha Pharmaceutical, balancing the continuity of tradition and innovation, provide significant implications and practical guidelines for Korean SMEs for their survival and sustainable management, which is an economic and business aspect of sustainability.
\end{abstract}

Keywords: firm longevity; centenarian companies; centennial firms; firm survival; Republic of Korea; sustainable management; Dongwha Pharmaceutical; business case; SMEs (small and medium enterprises); economic and business aspect of sustainability

\section{Introduction}

Considering their significant impacts on national economy, local communities, employees, suppliers, and other stakeholders, firm survival is an important goal for most companies [1]. However, firm longevity is not an easy result to achieve, and it becomes more and more difficult as business environments and paradigms shift dramatically. According to McKinsey, the average life span of companies listed in Standard and Poor's 500 was 61 years in 1958, but it fell to less than 18 years in 2016. What is even worse is that McKinsey forecasted that 75\% of the current Standard and Poor's 500 companies will not survive by 2027 [2].

In 2008, based on a study covering 41 countries (including those from Asia, Africa, Europe, North America, South America, and Oceania), the Bank of Korea reported that 5586 companies survived over 200 years; 3146 from Japan (56.3\%), 837 from Germany $(15.0 \%), 222$ from The Netherlands (4.0\%), and 196 from France (3.5\%) [3]. More than half of the over 200-year-old companies in the world are located in Japan. In Japan, there are seven companies that are older than 1000 years and 32 companies that are older than 500 years. In addition, many Japanese centenarian companies, called shinise, are mostly family inherited small and medium enterprises (SMEs), covering diverse industries, including manufacturing, wholesale, retail, service, and so on. Germany also has many 
centenarian companies, especially in the manufacturing industry, and over $95 \%$ of them are based on family businesses [4]. However, in the Republic of Korea, there are no companies more than 200 years old.

The Korea Federation of SMEs reported companies over 100 years old in 2018; 33,079 from Japan, 12,780 from the United States, 10,073 from Germany, and 3357 from The Netherlands. While the Republic of Korea has over 4000 years of history, when the company called Pochinchai (a printing company, founded in 1912) closed its business in 2019, Korea was left with only seven companies with over 100 years of history; Doosan Corporation (one of the conglomerates, founded in 1896), followed by Dongwha Pharmaceutical (a pharmaceutical company, founded in 1897), Shinhan Bank (a commercial bank, its old name was Hansung Bank, founded in 1897), Woori Bank (a commercial bank, its old name was Commercial Bank of Korea, founded in 1899), Monggo Foods (a soybean sauce manufacturer, founded in 1905), Kwangjang Market (a traditional Korean market, founded in 1911), and Sung Chang (a veneer manufacturer, founded in 1916) [4]. These results indicate that centenarian companies in Korea are very limited, and even after surviving over a hundred years, they continue to face severe challenges they need to overcome in order to survive. However, it is not clearly proven what factors affect the survival of companies for over a century.

As SMEs contribute to the economic development and survival of a country by encouraging economic growth and creating jobs [5], it is important to investigate the secrets of firm longevity for sustainable management, which has become more difficult than ever. However, the theoretical aspect of this problem has not been developed sufficiently, since the sample size is extremely small, data access to private SMEs (not listed on the stock market) is limited, and there are very limited studies on firm longevity. Thus, the findings from this case study of Dongwha Pharmaceutical, balancing the continuity of tradition and innovation, provide significant implications and practical guidelines for the survival of Korean SMEs through sustainable management, which is an economic and business aspect of sustainability.

The rest part of this paper is organized as follows: the next section presents theoretical development with relevant literature followed by a business case of Dongwha Pharmaceutical with detailed information, followed by a conclusion, managerial implications, limitations, and future research for firm longevity.

\section{Centenarian Companies}

According to the founder of modern management, Peter Drucker, firm survival is very important [1]. In his article titled "Will the corporation survive?", he answered with "Yes, but not as we know it [6]". This implies that survival is not easy, and companies must change to survive.

Despite the importance of firm longevity, there are very few studies on this issue, and they are primarily based on organizational theory and business strategy. Studies on organizational theories have investigated firm survival, focusing on external environmental conditions (the degree of competition, density, industry life cycle, and so on) and time varying conditions (mainly firm age and size) [7]. On the other hand, the field of corporate strategy focuses on firms' internal factors to conduct firm-level analyses, mainly based on a resource-based view (RBV). According to the RBV, companies can acquire their own core competencies that are hard to copy, as each company has different resources and capabilities $[8,9]$. However, few studies have approached both the external (based on organization theories) and internal (based on strategy research) factors to prove how firms achieve longevity, as it is complicated to integrate the internal and external perspectives for firm longevity $[7,10]$. While previous studies tried to explain certain factors for firm longevity, including firm age, firm maturity, firm size, history, various capabilities, culture, industry characteristics, and so on, there are no clear explanations or solutions. In addition, from the RBV-based perspective, there still exist some controversies regarding firm longevity, particularly whether companies should pursue changes as opposed to continuities [7,11]. 
While the theoretical foundation on firm longevity is not solid, it is possible to find more detailed strategies for the long-term survival of companies from Japanese centenarian companies. Iwasaki and Kanda investigated 90 established Japanese SMEs, ranging from 100 to 1277 years old, focusing on the unique characteristics of their long-term survival. Based on the study, they suggested three sacred principles of old established companies:

- Continuity of business and brand (e.g., long-lived business, brand, and goodwill);

- Succession of the founding family; and

- Corporate philosophy, principles, and family precepts.

In addition, they draw eight rational behaviors of survival:

- Observation of traditions;

- Developing new products and new businesses;

- Modernization of management systems;

- Succession and changes in technology;

- Search for new suppliers and customers;

- Inheritance of unique technology;

- Maintaining good transaction relationships (with suppliers, customers, and communities); and

- Succession by the founding family.

Moreover, they expect that these rational behaviors have positive effects on brand or goodwill, accumulated technology, close connection with the community, and unchanging traditional products, as well as negative effects of firm inflexibility and an old image of the company [12].

Based on the same data, TenHaken [13] suggested three common successful factors for centenarian companies, which is a perspective different from Iwasaki and Kanda [12]:

- Clarity and continuity of corporate culture and values;

- Learning systems built on relationships; and

- The ability to balance tradition and innovation through gradual change.

Similar to Collin's Build to Last [14], TenHaken's first factor, "clarity and continuity of corporate culture and values", is associated with the following five behaviors [13]:

- Keep businesses within the family;

- Maintain original brand names;

- Observe traditions;

- Inheritance of unique technology; and

- Maintain traditional products or services.

Focusing on relationships, specific behaviors for learning systems built on relationships include the followings [13]:

- Treat suppliers and customers as true partners;

- Learn from relationships (customers, suppliers, and distributors);

- Accumulated technology (internally and with partners, developing technological capabilities); and

- Obligation of local communities.

Finally, to balance tradition and innovation, TenHaken [13] proposed the following three behaviors:

- Up-to-date management methods;

- $\quad$ Search for new suppliers and customers; and

- $\quad$ Focus on developing new products and new businesses.

While the two studies of Iwasaki and Kanda [12] and TenHaken [13] provide valuable insights into this under-researched area regarding firm longevity, as there exist some discrepancies in terms of classification and categorization of the successful strategies for firm longevity, a well-classified framework to draw successful strategies for long-term survival of companies is required. For this reason, based on the findings from these two 
studies, as well as the major controversies of strategy research (changes vs. continuities) [7, 11], the author proposes the following framework with a focus on (1) the continuity of tradition and (2) innovation. In the following chapter, Dongwha Pharmaceutical is analyzed based on the ten successful strategies, incorporating six strategies for the continuity of tradition and four strategies for innovation, shown in Table 1.

Table 1. Strategies of long-term survival from Japanese centenarian companies.

\begin{tabular}{|c|c|c|}
\hline \multirow{2}{*}{ Focus } & \multicolumn{2}{|c|}{ Strategies } \\
\hline & Iwasaki and Kanda (1996) & TenHaken (2008) \\
\hline \multirow{6}{*}{ Continuity of tradition } & Long-lived business, brand, and goodwill & Maintain the original brand name \\
\hline & Observation of traditions & $\begin{array}{l}\text { Observe traditions } \\
\text { Maintain traditional products or services }\end{array}$ \\
\hline & $\begin{array}{l}\text { Inheritance of unique technology (succession of } \\
\text { technology) }\end{array}$ & Inheritance of unique technology \\
\hline & $\begin{array}{l}\text { Corporate philosophy, principles, and family } \\
\text { precepts }\end{array}$ & Continuity of corporate culture and values \\
\hline & Succession by the founding family & Keep the business within the family \\
\hline & $\begin{array}{l}\text { Maintaining good transaction relationships (with } \\
\text { suppliers, customers, and communities) }\end{array}$ & $\begin{array}{l}\text { Treat suppliers and customers as true partners } \\
\text { Learn from relationships (customers, suppliers, } \\
\text { and distributors) } \\
\text { Obligation of local communities }\end{array}$ \\
\hline \multirow{4}{*}{ Innovation } & Modernization of management systems & Up-to-date management methods \\
\hline & Developing new products and new businesses & $\begin{array}{l}\text { Focus on developing new products and } \\
\text { businesses }\end{array}$ \\
\hline & New technology (changes in technology) & $\begin{array}{l}\text { Accumulated technology (developing } \\
\text { technological capabilities) }\end{array}$ \\
\hline & Search for new suppliers and customers & Search for new suppliers and customers \\
\hline
\end{tabular}

\section{Sustainable Management of Dongwha Pharmaceutical over 100 Years}

Dongwha Pharmaceutical was founded in 1987 by a Korean national patriot with the same name. Its first and current signature product was Whal Myung Su (see Figure 1, meaning "lifesaving water"), a liquefied digestive medicine based on both oriental herbs and Western medicinal prescriptions. The company achieved four records in the Guinness Book of Records for being the oldest manufacturing company as well as the oldest pharmaceutical company in the Republic of Korea (both from 25 September 1897), having the oldest registered trademark (see fan in Figure 2) in the Republic of Korea (since 15 August 1910), and having the oldest registered product (Whal Myung Su, from 16 December 1910). Its signature product, Whal Myung Su, has sold over 8.5 billion bottles, and its market share in the Korean digestive market is about 70\% [15].

From the perspective of the continuity of tradition, Dongwha Pharmaceutical has maintained its original brand name, traditional products (based on the unique prescription from the loyal court), and long-lived business for the past 124 years. While the company was not succeeded by the founder's family because of the history of Japanese colonialism - the company was inherited by another national patriot's family in 1937—their corporate philosophy is still enshrined: (1) Dongwha serves customers by making effective medicines (importance of customers and quality of products); (2) Dongwha treads the path of virtue (corporate ethics); (3) Dongwha is a family whose members are willing to work diligently and live fruitful lives (loyalty of employees); and (4) all the staff of Dongwha admit and correct their mistakes in business and turn them into opportunities (responsibility of employees). The company went through a period of considerable turbulence in the Republic of Korea, marked by Japanese colonialism (1910-1945), the 
Korean War (1950-1953), and Korean industrialization led by Korean conglomerates (called "chaebol") (since the 1960s). Even having experienced such a tumultuous history, based on the company's philosophy, Dongwha was the center of liaison offices to support the Korean Independence Movement and financially supported the national enlightenment movement during the Japanese colonial period. In addition, when they faced cutthroat competition from other imported foreign medicines and new domestic medicines, the company overcame the challenges through win-win strategies with their traditional partners (wholesale pharmaceutical distributors) [15]. Even based on valuable traditions, under many challenges and environmental changes, long-term survival of Donghwa was not possible without continuous efforts toward changes while protecting core competencies. Thus, the right balance between tradition and innovation is a key success factor [13].
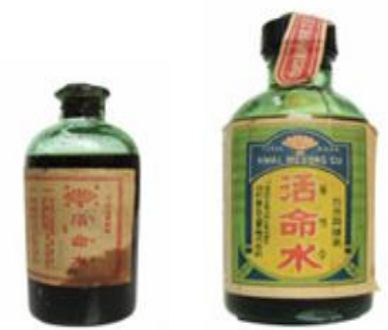

1897
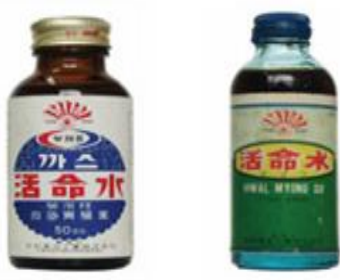

1969
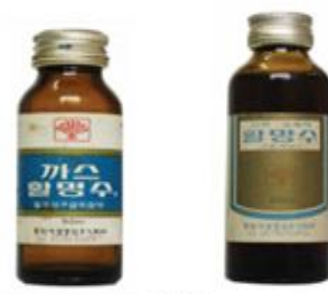

1982

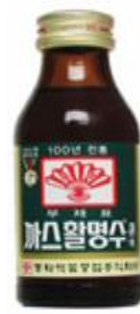

2004

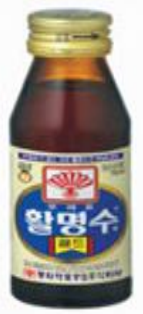

2007
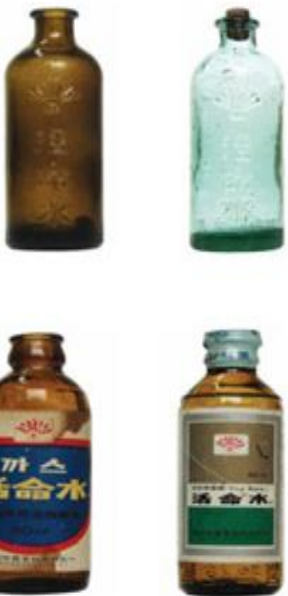

1971
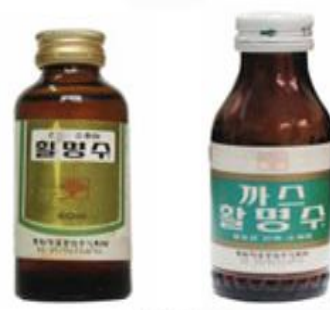

1987
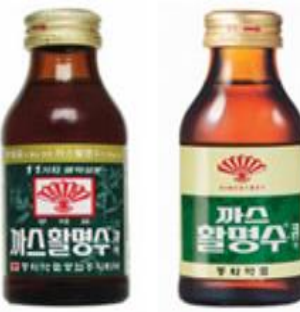

2008
2009

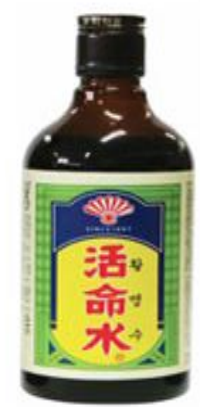

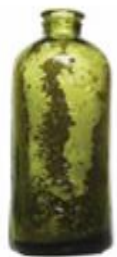
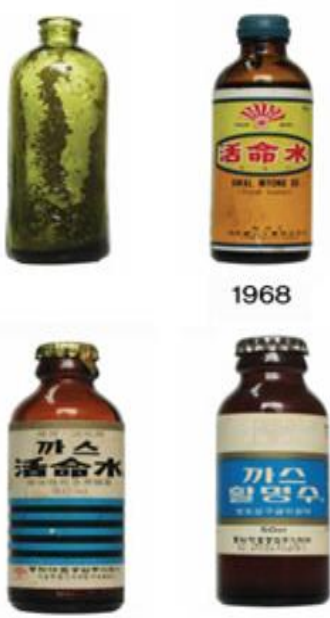

1982

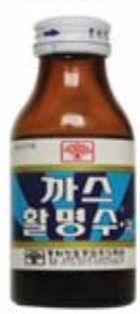

1992

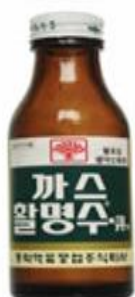

1999

Figure 1. The innovation of Dongwha Pharmaceutical's signature medicine, "Lifesaving Water", since 1897. Source: Korean Culture and Information Service (https: / / www.kocis.go.kr/) (accessed on 10 August 2021). 


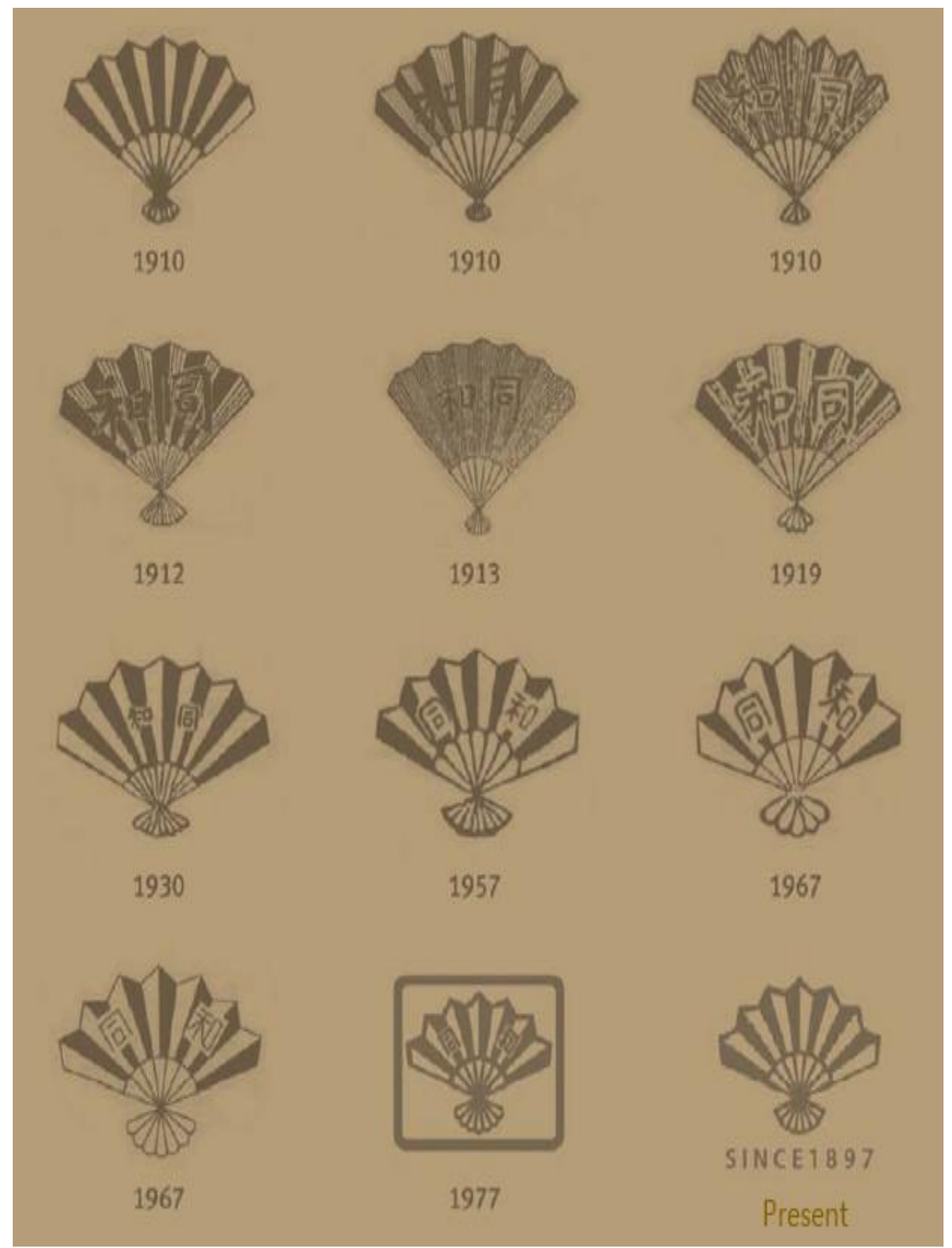

Figure 2. The evolution of the fan logo of Dongwha Pharmaceutical (registered trademark since 1910). Source: Dongwha Pharmaceutical Brochure.

Analyzing Dongwha Pharmaceutical from the perspective of innovation, the company did not stubbornly maintain its traditions without innovation. Dongwha Pharmaceutical's revenue in 2020 of KRW 272.1 billion (about USD 0.23 billion) and net profit in 2020 of KRW 28.7 billion (about USD 0.02 billion) [16] is based on its over 200 pharmaceutical products. The company's survival and financial performance are based on continuous innovation efforts. Dongwha Pharmaceutical exercised diverse efforts, including marketing (innovation on its brand, logo, advertising, and products), continuous technological developments through research and development $(\mathrm{R} \& \mathrm{D})$, new distribution channels, and new corporate social responsibilities (CSR) to keep up with the times. 
First, its signature product Whal Myung Su has changed over time, not only in terms of traditional ingredients (keeping the original recipe with herbs while adding carbonic acid and other newer ingredients to meet customers' changing tastes and needs), but also in terms of its packaging, as shown in Figure 1. The figure shows that Whal Myung Su has been modified several times while maintaining the original name and tradition.

Second, to efficiently respond to its domestic and foreign competitors and many upcoming similar products, as well as to position itself as one of the most representative brands in the Republic of Korea, the company created its trademark fan in 1910 (the first trademark in the Republic of Korea), and gradually changed it over the past 111 years. From Figure 2, it can be seen that the fan logo (meaning harmony) maintains its original shape but has evolved and modernized over time.

Third, to obtain a friendly image in the hearts and minds of their customers, the company had celebrities in each period as its advertisement models. In addition, to modernize Whal Myung Su by reflecting young generations' tastes and attracting the attention of younger customers, the company has continuously launched a special edition of Whal Myung Su in collaboration with popular domestic and national brands, artists, or TV programs such as "Kakao", "Guess", and a popular hip hop survival program "Show Me The Money", as shown in Figure 3, while keeping the original ingredients and identity with the original fan logo [15].

While the company started with Whal Myung Su, Whal Myung Su is not Dongwha Pharmaceutical's only product. The company improved its research and development (R\&D) capabilities through an internal research center (launched in 1973) as well as partnerships with many advanced pharmaceutical companies from the United States, Switzerland, Denmark, France, Italy, Japan, and so on. Based on its continuous R\&D efforts, the company has developed and sold over 200 pharmaceutical products, including Fucidin ointment (a topical antibiotic launched in 1980; its current market share in the domestic ointment market is about $60 \%$, dominant market share \#1 in its category) and Pancold (a cold medicine launched in 1968; its market share in the domestic cold medicine market is about $10 \%$, market share \#2 in its category). To grow from the oldest pharmaceutical company to a global leading pharmaceutical company, the company is exporting its new synthetic quinolone antibacterial compound, called Zabolante, to China, Mexico, the Middle East, and South Africa. In addition, the company obtained patents for its novel diabetic nephropathy drug in eight countries around the world, including the United States, Europe, and Japan. Moreover, Dongwha Pharmaceutical continues to conduct research on cardiovascular and metabolic diseases, and to develop innovative medicines in the fields of oncology, antibiotics, and immune diseases. These efforts make it possible for the company to export its active pharmaceutical ingredients (APIs) and finished products to over 30 countries, including the United States, Switzerland, Portugal, Australia, Philippines, Mexico, and so on [15].

Since the 1960s, as the cutthroat competition in the domestic pharmaceutical industry has intensified, Dongwha Pharmaceutical did not solely depend on their traditional partners (wholesale distributors). The company expanded its distribution networks through direct transactions with pharmacies and hospitals, having their own sales branches throughout the country. In addition, while keeping the traditional networks, the company executed strategic decisions to diversify and expand its business to convenience stores (CVSs) and supermarkets, which currently contribute $30 \%$ of their sales [15]. 

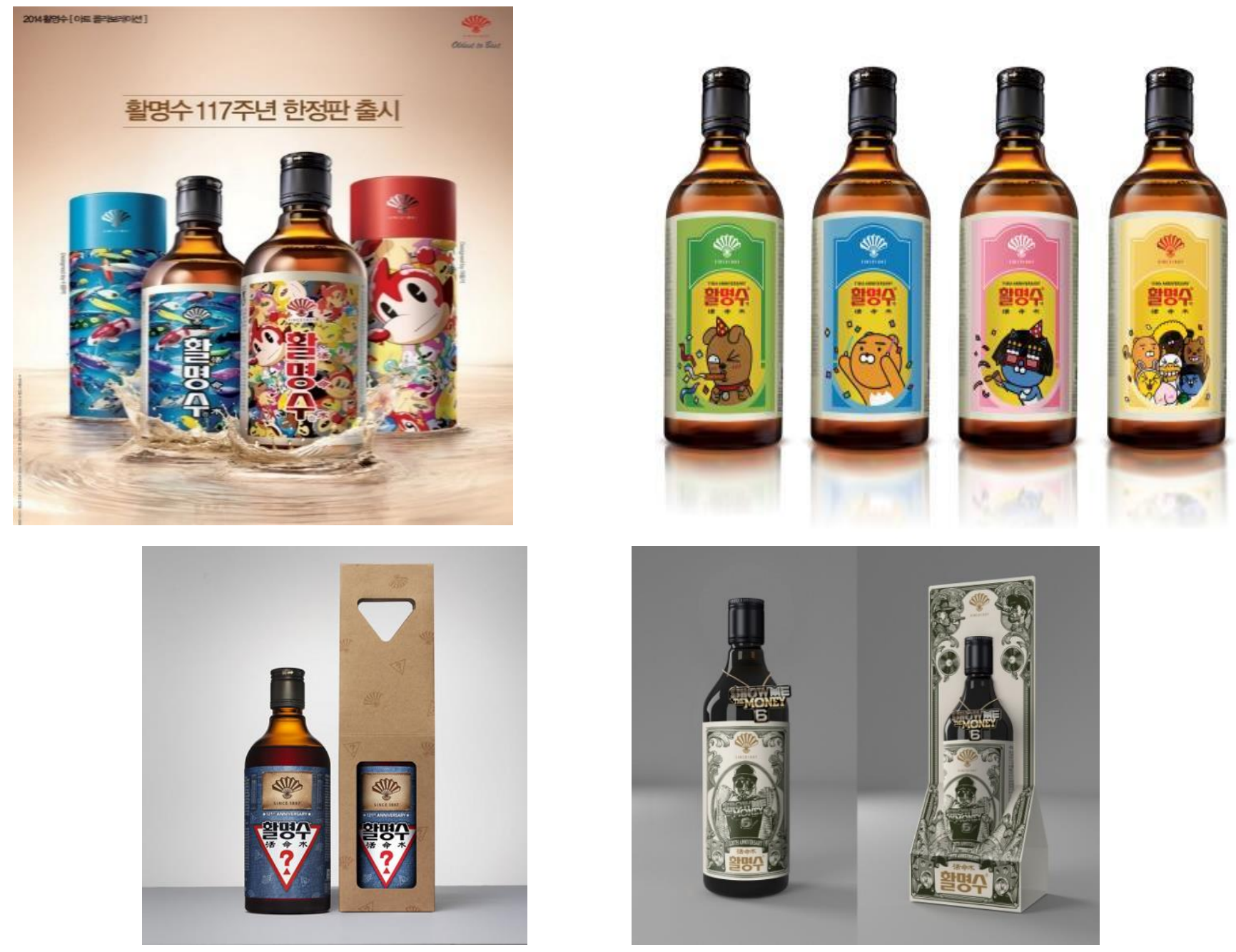

Figure 3. Special editions of Dongwha Pharmaceutical's signature medicine, "Lifesaving Water". Source: Dongwha Pharmaceutical Homepage (https:/ / www.dong-wha.co.kr/) (accessed on 10 August 2021).

Finally, based on the philosophy of Whal Myung Su, meaning "lifesaving water", Dongwha Pharmaceutical contributes to society through its "Lifesaving Water Campaign", which provides clean water to people in African countries without a sufficient supply of safe drinking water. In celebration of World Water Day, the campaign was held in partnership with the United Nations Children's Fund (UNICEF), as shown in Figure 4. As a corporate social responsibility (CSR) activity, a certain proportion of the sales of Whal Myung Su was used to send clean water to children who suffered from a shortage of drinking water, to purify drinking water, and to build clean wells in Africa [15]. 


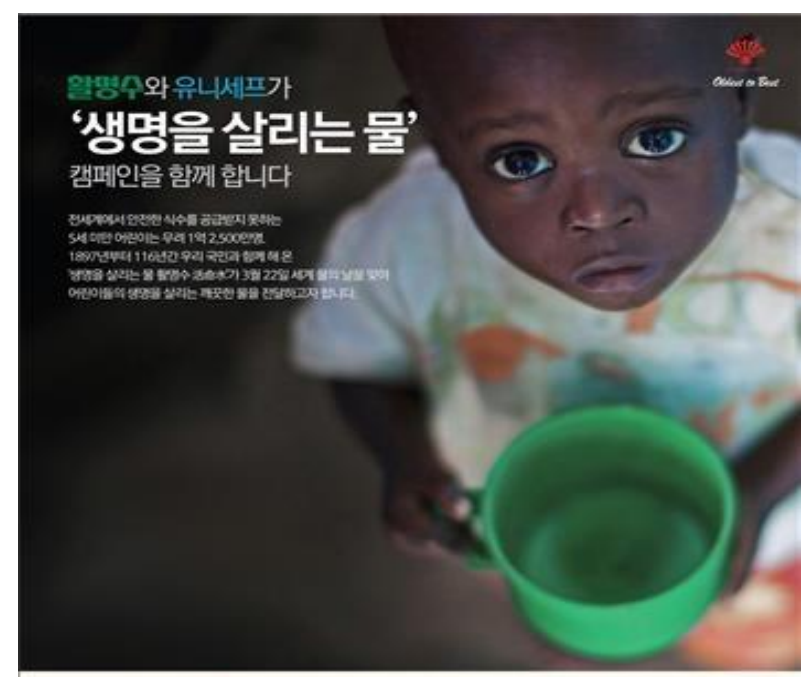

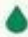

생명울 살라는 알 경폐인 생명울 살리는 알 형펴인

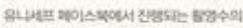

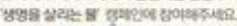

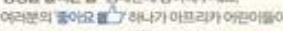

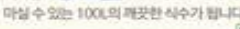

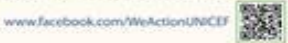

공학악풀
숭

‘생명올 살리는 물 : 왈영수 话命木'展

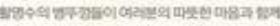

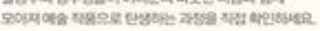
1.

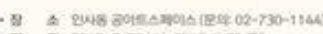

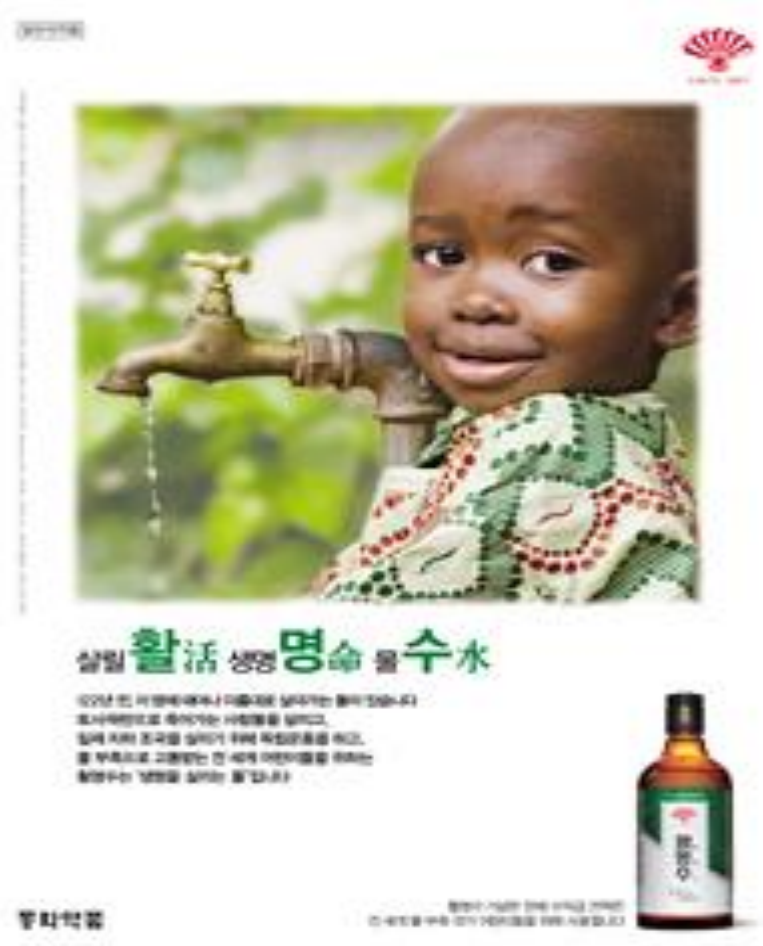

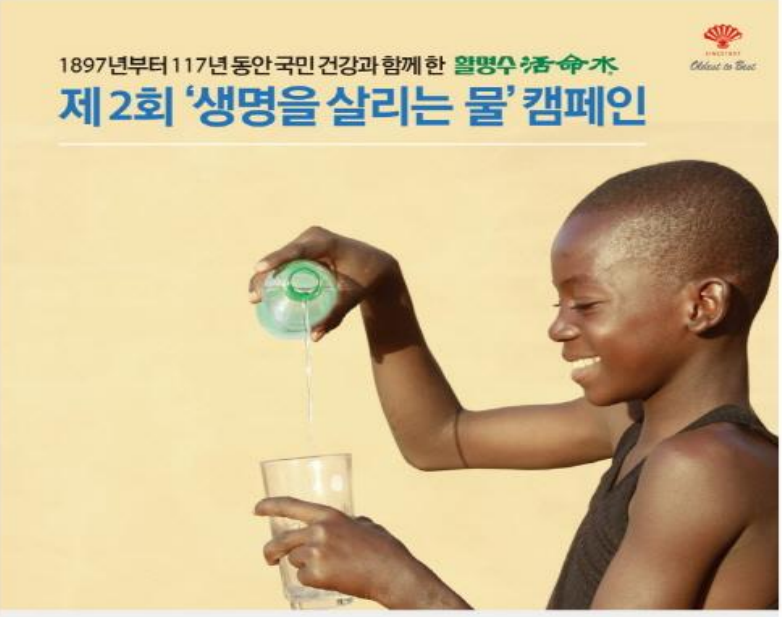

세계 물의 날 살릴 话, 생명 웅, 물가가 생명을 살리는 물을 전달합니다 여러분의 참여가 아프리카 물부족국가 어린이들이 마실 수 있는 깨꼿한 식수가 됩니다. 기간: 2014년 3월 한달 간

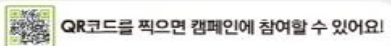

돟학약품

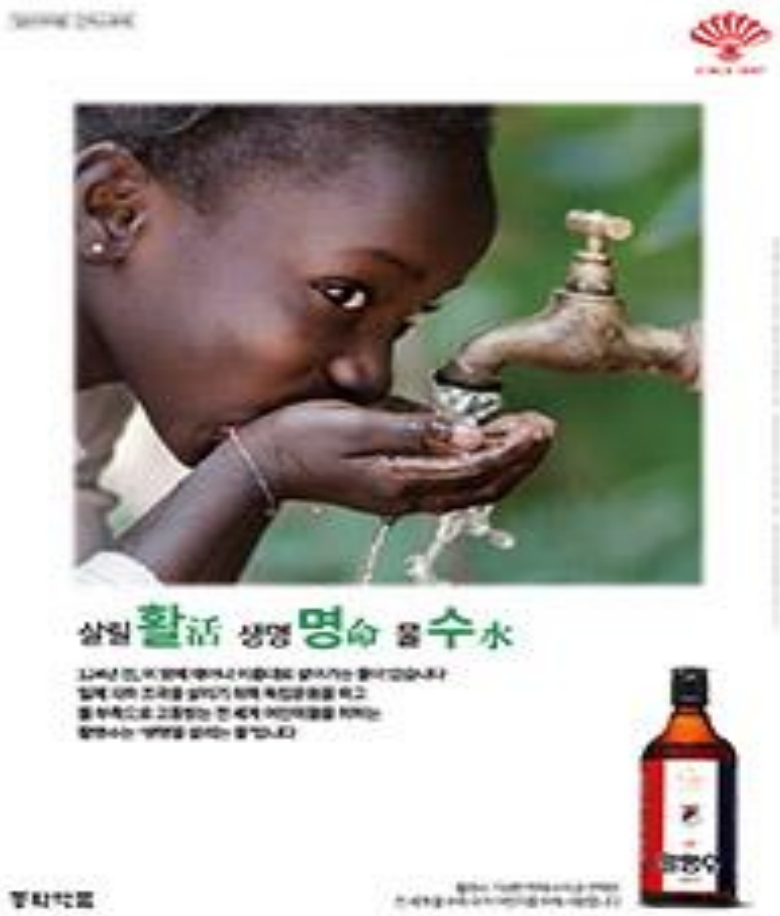

Figure 4. Dongwha Pharmaceutical's Lifesaving Water Campaign for kids in Africa. Source: Dongwha Pharmaceutical Homepage (https:/ / www.dong-wha.co.kr/) (accessed on 10 August 2021).

\section{Conclusions and Discussion}

To provide significant implications and practical guidelines for Korean SMEs for their survival and sustainable management, which is an economic and business aspect of sustainability, this study reviewed previous studies on firm longevity and analyzed Dongwha Pharmaceutical, the oldest pharmaceutical company and the oldest manufacturer in Korea. 
In Korea, it is very difficult to sustain a business for 100 years. Even for the companies that already survived over 100 years, it is not guaranteed whether they will sustain further, as there are no clear practical guidelines to follow for managers and policy makers. However, while it is very rare for a company to survive over a hundred years in the Republic of Korea, Dongwha Pharmaceutical has grown its entrepreneurial philosophy and has been loved continuously by its customers.

For Korean SMEs' sustainable management over 100 years, it is critical to balance the continuity of tradition and innovation. Based on Iwasaki and Kanda [12] and TenHaken [13], this study proposes strategies for the long-term survival of companies. For the continuity of tradition, companies must maintain their original brand name and business, observe traditions, inherit unique technology, keep the corporate philosophy, keep the family business, and maintain good transaction relationships with suppliers, customers, and communities. From the perspective of innovation, companies need to modernize their management systems, develop new products and businesses, develop new technologies, and develop new suppliers and customers.

However, firm longevity is not easily achieved because adhering to tradition may keep a company behind the times, and executing extreme innovations may undermine its traditions. In addition, it is very difficult to define how and to what degree companies need to balance the continuity of tradition and innovation. Under this circumstance, it is very challenging for many company managers to develop and execute detailed long-term plans and strategies to become centenarian companies and survive. Therefore, managers and policy makers need to know practical details on how and to what degree of innovation and tradition are appropriate to maintain and survive as centenarian companies. While it is impossible to quantitatively define the harmonious weight of the balance between the continuity of tradition and innovation, the case of Donghwa Pharmaceutical provides a valuable example and perspective on what to change versus maintain, as well as how to wisely balance the continuity of tradition and innovation.

In summary, inherited by national patriots, Dongwha Pharmaceutical has maintained its original brand name and traditional products, and has been a long-lived business for the past 124 years; their corporate philosophy regarding the importance of customers and quality of products, corporate ethics, loyalty of employees, and employees' responsibilities is still enshrined in their operations. Even based on valuable traditions, when they faced competition from other imported foreign medicines and new domestic medicines, the company overcame the challenges through win-win strategies with their partners. In addition, to keep up with the times, the company exercised diverse efforts, including marketing (innovation on its brand, logo, advertising, and products), continuous technological developments through R\&D, new distribution channels, and new corporate social responsibilities. The long-term survival was not possible without continuous efforts toward changes while protecting core competencies. As firm longevity for sustainable management, especially for SMEs, is of greater importance now than ever before, the findings from this study provide significant implications for companies and policy makers.

There are some limitations in conducting this research. While this research is focused on investigating firm longevity, because of limitations such as firm data access, limited samples (especially in the Republic of Korea), and limited theories regarding centenarian companies, this case study relies on the business case of Dongwha Pharmaceutical. While previous sustainability studies (e.g., Kang [5]) found that the priority for survival and sustainable business is firm profitability based on large-scale quantitative data, the results are not enough to explain firm longevity. Thus, a more quantitative approach as well as a qualitative approach based on the perspective of economic history and development covering diverse industries and countries will be necessary in the future research in order to develop a more complete and detailed understanding of firm longevity for sustainable management. Future research may develop more rigorous theories and comparisons across industries and countries to contribute to the economic and business aspect of sustainability. 
Funding: This research received no external funding.

Institutional Review Board Statement: Not applicable.

Informed Consent Statement: Not applicable.

Conflicts of Interest: The author declares no conflict of interest.

\section{References}

1. Drucker, P.F. The Practice of Management; Harper \& Row: New York, NY, USA, 1954.

2. Garelli, S. Why You Will Probably Live Longer Than Most Big Companies. IMD. 2016. Available online: https://www.imd.org/ research-knowledge/articles/why-you-will-probably-live-longer-than-most-big-companies/ (accessed on 10 August 2021).

3. The Bank of Korea. The Factors and Implications of Japanese Corporate Longevity. 2008. Available online: https://www.bok.or.kr/ viewer/skin/doc.html?fn=FILE_201803300723135521.pdf\&rs=/webview/result/P0000537/200805 (accessed on 10 August 2021).

4. The Korea Chamber of Commerce \& Industry. KCCI Brief. 2019. Available online: https://lobbymap.org/influencer/KoreaChamber-of-Commerce-and-Industry-KCCI-172462ede3f0d1d6a46d9dcac634c456 (accessed on 10 August 2021).

5. Kang, M.Y. Sustainable Profit versus Unsustainable Growth: Are Venture Capital Investments and Governmental Support Medicines or Poisons? Sustainability 2020, 12, 7773. [CrossRef]

6. Drucker, P.F. Will the Corporations Survive? Yes, but not as We Know It. Economist 2001. Available online: https://www. economist.com/special-report/2001/11/03/will-the-corporation-survive (accessed on 10 August 2021).

7. Napolitano, R.N.; Marino, V.; Ojala, J. In search of an integrated framework of business longevity. Bus. Hist. 2015, 57, 955-969. [CrossRef]

8. Barney, J. Firm resources and sustained competitive advantage. J. Manag. 1991, 17, 99-120. [CrossRef]

9. Wernerfelt, B. A resource-based view of the firm. Strat. Manag. J. 1984, 5, 171-180. [CrossRef]

10. Sasaki, I.; Sone, H. Cultural approach to understanding the long-term survival of firms-Japanese Shinise firms in the sake brewing industry. Bus. Hist. 2015, 57, 1020-1036. [CrossRef]

11. Hogarth, R.M.; Michaud, C.; Doz, Y.; Van der Heyden, L. Longevity of Business Firms: A Four-Stage Framework for Analysis; INSEAD Working Paper No. 91/55/EP/SM; INSEAD: Fontainebleau, France, 1991.

12. Iwasaki, N.; Kanda, M. Sustainability of the Japanese Old Established Companies; Economic Institute of Seijo University: Tokyo, Japan, 1996.

13. TenHaken, V. Lessons learned from comparing survival behaviors of very old Japanese and American companies. Int. Bus. Econ. Res. J. 2008, 7, 67-74. [CrossRef]

14. Collins, J.; Porras, J. Built to Last: Successful Habits of Visionary Companies; HarperCollins Publishers: New York, NY, USA, 1994.

15. Dongwha Pharmaceutical. Available online: https://www.dong-wha.co.kr/ (accessed on 10 August 2021).

16. Financial Supervisory Service. Available online: https://opendart.fss.or.kr/disclosureinfo/fnltt/singl/main.do (accessed on 10 August 2021). 